\title{
About the Radical Formation in the Pyrolysis of Formic Acid at High Temperatures
}

\author{
M. Klatt, M. Röhrig, and H. Gg. Wagner \\ Institut für Physikalische Chemie, Universität Göttingen, Göttingen \\ Z. Naturforsch. 47a, 1138-1140 (1992); received September 12, 1992
}

The formation of radicals in the $\mathrm{HCOOH}$ pyrolysis was investigated in the temperature and density range between 1450 and $2450 \mathrm{~K}$ and $2 \cdot 10^{-6}$ and $1.2 \cdot 10^{-5} \mathrm{~mol} / \mathrm{cm}^{3}$, respectively. The small amount of radicals found indicates that a radical forming reaction path in the formic acid pyrolysis is smaller than $0.2 \%$ of the total decomposition rate.

\section{Introduction}

Formic acid $(\mathrm{HCOOH})$ is an important intermediate in the oxidation of unsaturated hydrocarbons in combustion processes as well as in atmospheric reactions. For example, $\mathrm{HCOOH}$ is the main product in the $\mathrm{O}_{3}-\mathrm{C}_{2} \mathrm{H}_{4}$ reaction [1]. It has been proposed that $\mathrm{HCOOH}$ is formed highly excited in the reaction of $\mathrm{O}_{2}$ with $\mathrm{CH}_{2}$ [2] where its subsequent decomposition into $\mathrm{CO}$ and $\mathrm{H}_{2} \mathrm{O}$ and radical products has been investigated previously $[3,4]$.

The decomposition of formic acid is possible via several channels (thermodynamic data from [5]):

\begin{tabular}{rlrc} 
& & & $\Delta_{r} H(\mathrm{~kJ} / \mathrm{mol})$ \\
\hline $\mathrm{HCOOH}$ & $\rightarrow \mathrm{CO}_{2}+\mathrm{H}_{2}$ & -7 \\
& $\rightarrow \mathrm{CO}+\mathrm{H}_{2} \mathrm{O}$ & 24 \\
& $\rightarrow \mathrm{H}+\mathrm{COOH}$ & 411 \\
& $\rightarrow \mathrm{CO}_{2}+2 \mathrm{H}$ & 429 \\
& $\rightarrow \mathrm{HCO}+\mathrm{OH}$ & 466 \\
& $\rightarrow \mathrm{H}+\mathrm{HCOO}$ & 480 \\
\hline
\end{tabular}

Decomposition rate of $\mathrm{HCOOH}$ and the product distribution have been investigated by several authors $[6,7]$. The apparent activation energies of the $\mathrm{HCOOH}$ decomposition have been found to be $209 \mathrm{~kJ} / \mathrm{mol}$ [6] or $168 \mathrm{~kJ} / \mathrm{mol}$ [7] for the $\mathrm{CO}$ channel and $238 \mathrm{~kJ} / \mathrm{mol}$ [6] or $254 \mathrm{~kJ} / \mathrm{mol}$ [7] for the $\mathrm{CO}_{2}$ channel. It has been assumed that only the stable products $\mathrm{CO}_{2}+\mathrm{H}_{2}$ and $\mathrm{CO}+\mathrm{H}_{2} \mathrm{O}$ are formed, but only the formation of $\mathrm{CO}$ and $\mathrm{CO}_{2}$ has been measured directly, and the ratio of

Reprint requests to Prof. Dr. H. Gg. Wagner, Institut für Physikalische Chemie, Universität Göttingen, Tammannstraße 6, W-3400 Göttingen, Germany.
$\mathrm{CO}$ and $\mathrm{CO}_{2}$ is reported [7] to be

$$
\alpha=[\mathrm{CO}] /\left[\mathrm{CO}_{2}\right]=0.16 \exp (-10200 \mathrm{~K} / T) .
$$

In [6] the $\mathrm{CO} / \mathrm{CO}_{2}$ ratio is reported to be one at $2000 \mathrm{~K}$ and to be about 20 at $800 \mathrm{~K}$.

Yet, there has been no investigation of the contribution of a direct radical formation path such as $\mathrm{H}+\mathrm{COOH}$ or $\mathrm{HCO}+\mathrm{OH}$. These reaction paths are highly endothermic but with increasing temperature their contribution to the decomposition rate may be increasing too.

In this work we have checked the amount of $\mathrm{H}$ and $\mathrm{OH}$ formed in the $\mathrm{HCOOH}$ pyrolysis in the temperature range between 1600 and $2500 \mathrm{~K}$ with the intention to obtain an upper limit for the contribution of radical forming steps in the $\mathrm{HCOOH}$ decomposition.

\section{Experimental}

The experiments were carried out in two shock tubes; the one for the $\mathrm{OH}$ detection was made of aluminium with an inner diameter of $20 \mathrm{~cm}$, and the other for the $\mathrm{H}$ measurements was made of stainless steel and $8 \mathrm{~cm}$ diameter. The detection system for $\mathrm{OH}$ radicals by UV absorption consists of a frequency doubled ring dye laser pumped with an $\mathrm{Ar}^{+}$laser. The absorption was followed with photodiodes and measured by difference amplifying.

$\mathrm{H}$ atoms were monitored by H-ARAS with a microwave discharge lamp as light source. Both the shock tubes and the optical setups have been described in detail previously $[8-10]$. The detection limit of both systems was better than $2 \cdot 10^{-12} \mathrm{~mol} / \mathrm{cm}^{3}$.

The testgases used were prepared in a flow system. A small argon flow passed a thermostated saturator 


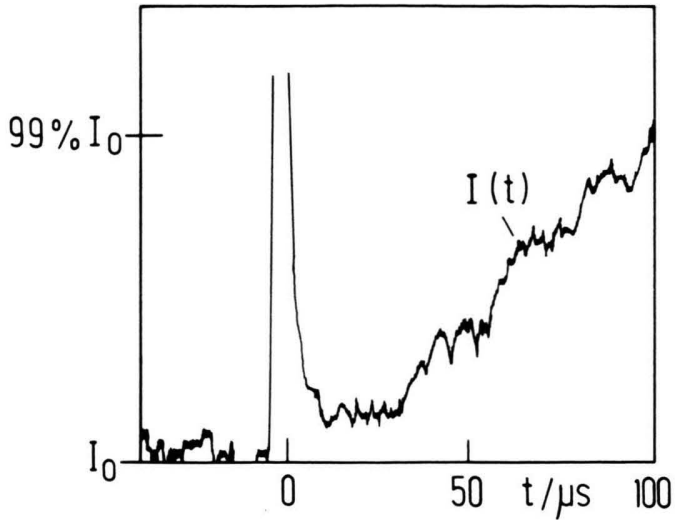

Fig. 1. Absorption profile of $\mathrm{OH}$ radicals at $\lambda=308.417 \mathrm{~nm}$ $\left(\mathrm{Q}_{1} 4\right.$-line), presented in real time; $T_{2}=2447 \mathrm{~K}, \varrho_{2}=2.1 \cdot 10^{-6}$ $\mathrm{mol} / \mathrm{cm}^{3}, 2200 \mathrm{ppm} \mathrm{HCOOH}$.

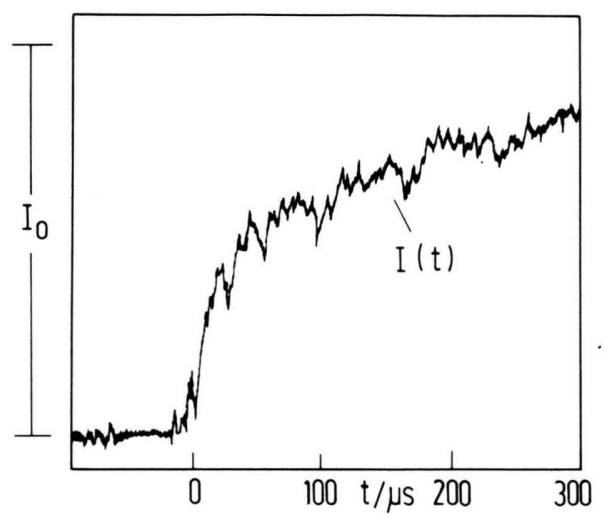

Fig. 2. Absorption signal of $\mathrm{H}$ atoms behind the reflected wave: $T_{2}=2243 \mathrm{~K}, \varrho_{2}=1.1 \cdot 10^{-5} \mathrm{~mol} / \mathrm{cm}^{3}, 820 \mathrm{ppm}$ $\mathrm{HCOOH}$.

filled with $\mathrm{HCOOH}$ and was mixed together with a flow of pure argon. Both flows were controlled by mass flow meters (Tylan Mass Flow Controller) with an accuracy of $\pm 2 \%$.

The substances used were $\mathrm{HCOOH}$ (p.a., 99.9\%, Merck), Argon (6.0) and $\mathrm{H}_{2}$ (3.0) as driver gas.

\section{Results and Discussion}

\section{OH Measurements}

The formation of $\mathrm{OH}$ radicals was investigated behind incident shock waves in the temperature range between 1400 and $2450 \mathrm{~K}$ and total densities around $(3 \pm 1) \cdot 10^{-6} \mathrm{~mol} / \mathrm{cm}^{3}$. The $\mathrm{HCOOH}$ concentration was varied between $4 \cdot 10^{-9}$ and $6 \cdot 10^{-9} \mathrm{~mol} / \mathrm{cm}^{3}$.
Figure 1 shows an absorption profile at $2446 \mathrm{~K}$ and an $\mathrm{HCOOH}$ concentration of $4.7 \cdot 10^{-9} \mathrm{~mol} / \mathrm{cm}^{3}$. After passage of the shock front indicated by the sharp schlieren signal the absorption rises slowly to a maximum value of about $1 \%$ within $100 \mu$ s, which corresponds to a concentration of less than $10^{-11} \mathrm{~mol} / \mathrm{cm}^{3}$ $\mathrm{OH}$ radicals, that is only $0.18 \%$ of the initial $\mathrm{HCOOH}$ concentration.

At that high temperature and that density decomposition rate constant of $\mathrm{HCOOH}$ is about $10^{5} \mathrm{~s}^{-1}$ $[6,7]$. That means that the $\mathrm{OH}$ signal observed cannot be due to a direct decomposition channel because its rise is too slowly. It is mainly due to the subsequent decomposition of $\mathrm{H}_{2} \mathrm{O}$ which is formed in the $\mathrm{HCOOH}$ pyrolysis, so that a direct $\mathrm{OH}$ channel in the $\mathrm{HCOOH}$ pyrolysis should be far below $0.2 \%$.

\section{H Measurements}

Lyman- $\alpha$-absorption experiments were performed in the temperature range between 1860 and $2250 \mathrm{~K}$ behind reflected shock waves. The total densities and the $\mathrm{HCOOH}$ concentration were around $(1.1 \pm 0.1)$ $\cdot 10^{-5} \mathrm{~mol} / \mathrm{cm}^{3}$ and $(6 \pm 3) \cdot 10^{-9} \mathrm{~mol} / \mathrm{cm}^{3}$, respectively.

The absorption profile shown in Fig. 2 was recorded at a temperature of $2250 \mathrm{~K}$ with an initial $\mathrm{HCOOH}$ concentration of $8.8 \cdot 10^{-9} \mathrm{~mol} / \mathrm{cm}^{3}$. After the reflected shock front the absorption rises within $400 \mu \mathrm{s}$ to an end value of about $84 \%$. That corresponds to a concentration of $\mathrm{H}$ atoms of $2.1 \cdot 10^{-11} \mathrm{~mol} / \mathrm{cm}^{3}$, which is only $0.2 \%$ of the initial $\mathrm{HCOOH}$ concentration.

Assuming that $\mathrm{HCOOH}$ decomposes completely into $\mathrm{CO}$ and $\mathrm{H}_{2} \mathrm{O}$, as proposed by Saito et al. [7], with a rate constant of $2.5 \cdot 10^{5} \mathrm{~s}^{-1}$ at the conditions applied in that experiment, the subsequent water decomposition produces about $2 \cdot 10^{-11} \mathrm{~mol} / \mathrm{cm}^{3}$ $\mathrm{H}$ atoms. That means that a prevailing part of the observed signal is also not due to a direct $\mathrm{HCOOH}$ pyrolysis channel but due to secondary reactions as seen in the $\mathrm{OH}$ measurements, and the direct $\mathrm{H}$ channel in the $\mathrm{HCOOH}$ pyrolysis should be also far below $0.2 \%$.

\section{Conclusion}

Both the $\mathrm{OH}$ and the $\mathrm{H}$ measurements, performed in the temperature and density range between 1400 
and $2450 \mathrm{~K}$ and $2 \cdot 10^{-6}$ and $1.2 \cdot 10^{-5} \mathrm{~mol} / \mathrm{cm}^{3}$, respectively, indicate that a radical forming step in the formic acid pyrolysis system is smaller than $0.2 \%$ of the total decomposition rate.

These radicals are formed to a good deal by water decomposition, and the water gas equilibrium $\left(\mathrm{CO}+\mathrm{H}_{2} \mathrm{O}=\mathrm{CO}_{2}+\mathrm{H}_{2}\right)$ will be established so that the direct radical channel in the $\mathrm{HCOOH}$ pyrolysis in fact may be estimated to be $\leq 10^{-4}$ of the total decomposition rate.

These results are in good agreement with previous assumptions of Shaub et al. [6] and Saito et al. [7]. The authors proposed that radical forming steps in the $\mathrm{HCOOH}$ pyrolysis are of minor importance because

[1] J. T. Herron and R. E. Huie, J. Amer. Chem. Soc. 99, 5430 (1977).

[2] D. S. Y. Hsu and M. C. Lin, Int. J. Chem. Kinet. 9, 507 (1977). - W. M. Shaub, D. S. Y. Hsu, T. L. Burks, and M. C. Lin, 18th Symp. (Int.) on Combust. (1981), p. 811.

[3] Ch. Dombrowsky; S. M. Hwang, M. Röhrig, and H. Gg. Wagner, Ber. Bunsenges. Phys. Chem. 96, 195 (1992).

[4] Ch. Dombrowsky and H. Gg. Wagner, Ber. Bunsenges. Phys. Chem., in print.

[5] C. F. Melius, private Communication, Sandia National Laboratories, Livermoore, California. of their strong endothermicity. This is well confirmed by our measurements. Even at the highest temperature investigated the contribution of a radical channel should in fact be far below $0.2 \%$.

That result is also in agreement with the small amount of radicals found in the reaction of $\mathrm{CH}_{2}$ with $\mathrm{O}_{2}[3,4]$. In this reaction $\mathrm{HCOOH}$ may be formed highly excited with an internal energy of about $740 \mathrm{~kJ} / \mathrm{mol}$. That energy is sufficiently high for a direct decomposition into $\mathrm{CO}+\mathrm{H}+\mathrm{OH}$ or $\mathrm{CO}_{2}+2 \mathrm{H}$, but the contribution of the radical steps has been found to be low.

The support of this work by the DFG is gratefully acknowledged.

[6] D. S. Y. Hsu, W. M. Shaub, M. Blackburn, and M. C. Lin, 19th Symp. (Int.) on Combust. (1982), p. 89.

[7] K. Saito, T. Kakumoto, H. Kuroda, S. Tonii, and A. Imamura, J. Phys. Chem. 80, 4989 (1984).

[8] K. Holzrichter and H. Gg. Wagner, 18th Symp. (Int.) on Combust. (1981), p. 769.

[9] M. Klatt, M. Röhrig, and H. Gg. Wagner, Ber. Bunsenges. Phys. Chem. 95, 1163 (1991).

[10] A. Hoffmann, M. Klatt, and H. Gg. Wagner, Z. Phys. Chem. N.F. 168, 1 (1990). 